\title{
Progress in Stroke: Marking the 30-Year Anniversary of Cerebrovascular Diseases
}

\author{
Craig S. Anderson
}

The George Institute for Global Health, Faculty of Medicine, University of New South Wales, Sydney, NSW, Australia

A recent stint of hospital clinical service on the neurology roster, incorporating 24/7 regional stroke calls, provided me with the impetus to reflect on the remarkable achievements that have been made in stroke care over the last three decades. Arguably, the most significant advance has been in "active management," where, for a long time, the attitude towards stroke has been one of therapeutic nihilism and that patients are to be considered as having little useful potential [1].

In 1991, there were no stroke units, thrombolysis, or standard assessment protocols for neurological impairment, disability, or dysphagia; an "early" CT scan was that done within $24 \mathrm{~h}$ of hospital admission; antihypertensive therapy was avoided or used cautiously for secondary prevention because of the perceived harm from compromising the cerebral circulation; and patients were often managed in single-bed side-rooms, with limited mobilization or assisted feeding, with a low threshold to using narcotics rather than antibiotics in the event of pneumonia.

However, this was a critical watershed in the history of stroke, which followed a period where the only tool, measurement, was refined through the science of epidemiology, in order to highlight the burden of stroke in popula-

karger@karger.com

(c) 2021 S. Karger AG, Basel

www.karger.com/ced

Karger tion-based incidence studies [2] and characterize the natural history of pathological stroke subtypes and patterns of neurological outcome in well-defined cohorts [3]. This was the time in which the science and craft of major endpoint, multicenter, randomized controlled trials of stroke were introduced to the world. The European Carotid Surgery Trial [4] and the North American Symptomatic Carotid Endarterectomy Trial [5] resolved uncertainties over the balance of benefits and harms of carotid endarterectomy for symptomatic, high-grade, internal carotid artery stenosis. The UK and Dutch transient ischemic attack (TIA) trials demonstrated the importance of aspirin for secondary prevention $[6,7]$. Subsequently, there was an acceleration in progress covering scientific inquiry, conferences, and societies, the establishment of the Cochrane Library [8] with a highly productive stroke group, the foundation meta-analysis of the benefits of stroke units [9], and the pivotal National Institute of Neurological Disorders and Stroke (NINDS) trial [10].

Reflection can simply be the careful consideration of how we have come to make time-critical decisions about reperfusion therapies, use door-to-needle time and other performance metrics for quality assurance, and organize interdisciplinary stroke services that extend beyond hos- 
pital boundaries as well as incorporating advanced communications, assessment protocols, discharge plans, and equipment and devices to assist with nursing care and rehabilitation. It could also include how we now readily communicate using various terms and scores like the NIHSS (National Institutes of Health Stroke Scale), the mRS (modified Rankin scale), and "core" and "mismatch" volumes, and have less debate over the use of treatments when they are evidence-based and are more cognizant to involve the patients and their families (who have ready access to information and high expectations) in decisionmaking.

A more nuanced form of reflection, though, allows greater value from a learning perspective. It involves the conscious consideration and analysis of how actions and beliefs arose. Such reflection gives the brain an opportunity to pause amidst the chaos, untangle and sort through observations and experiences, consider different interpretations, and create meaning to inform future mindset and actions.

Thus, as a way of celebrating this important year for the journal Cerebrovascular Diseases and the correspond- ing 10 years of Cerebrovascular Diseases EXTRA (which emphasizes research in clinical practice and evidence translation), we plan to publish a series of commissioned 30-year expert reviews in stroke. With the premise that "meaning making" can advance research and practice, these reviews aim to provide a historical perspective of advances in key areas of stroke, incorporating lessons learnt, current status, and future directions. This is an exciting year, and I look forward to your feedback, contributions, and ongoing support of these two journals.

\section{Conflict of Interest Statement}

CSA has received grant support, travel reimbursement, and honoraria from Takeda China.

\section{Funding Sources}

CSA receives fellowship and grant support from the National Health and Medical Research Council (NHMRC) of Australia.

\section{References}

1 Biller J, Love BB. Nihilism and stroke therapy. Stroke. 1991 Sep;22(9):1105-7.

2 Bamford J, Sandercock P, Dennis M, et al. A prospective study of acute cerebrovascular disease in the community: the Oxfordshire Community Stroke Project 1981-86. 1. Methodology, demography and incident cases of first-ever stroke. J Neurol Neurosurg Psychiatry. 1988;51:1373-80

3 Wade DT, Hewer RL. Functional abilities after stroke: measurement, natural history and prognosis. J Neurol Neurosurg Psychiatry. 1987 Feb;50(2):177-82.

4 Warlow C; European Carotid Surgery Trialists' Collaborative Group. MRC European Carotid Surgery Trial: interim results for symp- tomatic patients with severe (70-99\%) or with mild $(0-29 \%)$ carotid stenosis. European Carotid Surgery Trialists' Collaborative Group. Lancet. 1991 May;337(8752):1235-43.

5 Barnett HJ, Taylor DW, Haynes RB, Sackett DL, Peerless SJ, Ferguson GG, et al.; North American Symptomatic Carotid Endarterectomy Trial Collaborators. Beneficial effect of carotid endarterectomy in symptomatic patients with high-grade carotid stenosis. $\mathrm{N}$ Engl J Med. 1991 Aug;325(7):445-53.

6 Farrell B, Godwin J, Richards S, Warlow C; UK-TIA study group. The United Kingdom transient ischaemic attack (UK-TIA) aspirin trial: final results. J Neurol Neurosurg Psychiatry. 1991 Dec;54(12):1044-54.
7 van Gijn J, Algra A, Kappelle J, Koudstaal PJ van Latum A; Dutch TIA Trial Study Group. A comparison of two doses of aspirin $(30 \mathrm{mg}$ vs. $283 \mathrm{mg}$ a day) in patients after a transient ischemic attack or minor ischemic stroke. $\mathrm{N}$ Engl J Med. 1991 Oct;325(18):1261-6.

8 Chalmers I, Dickersin K, Chalmers TC. Getting to grips with Archie Cochrane's agenda. BMJ. 1992 Oct;305(6857):786-8.

9 Langhorne P, Williams BO, Gilchrist W, Howie K. Do stroke units save lives? Lancet. 1993 Aug;342(8868):395-8.

10 The National Institute of Disorders and Stroke rt-PA Stroke Study group: tissue Plasminogen activator for acute ischemic stroke. N Engl J Med. 1995;333(24):1581-8. 